\title{
ScIDoC
}

International Journal of Dentistry and Oral Science (IJDOS)

ISSN: $2377-8075$

\section{Comparative Study Of Effect Of Many Commercial Types Of Oxygen Inhibitors On Resin Cement}

Research Article

Ali Yousef ${ }^{1}$, Eyad Swed ${ }^{2}$, Kinan Saoud ${ }^{3}$, Muaaz Alkhouli ${ }^{*}$

${ }^{1}$ MSc in Fixed Prosthodontics, Faculty of Dentistry, Damascus University, Syria.

${ }^{2}$ Professor in Fixed Prosthodontics, Faculty of Dentistry, Damascus University, Syria.

${ }^{3}$ MSc in Oral and Maxillofacial Surgery, Faculty of Dentistry, Damascus University, Syria.

${ }^{4} \mathrm{MSc}$ in Pediatric Dentistry, Faculty of Dentistry, Damascus University, Syria.

\section{Abstract}

Purpose: The aim of this study is to compare the effect of many commercial types of oxygen inhibitors on color stability of resin cement.

Materials and Methods: A total of 40 specimens were prepared usingVariolink-N (, IvoclarVivadent AG, Schaan, Liechtenstein). Specimens were light-cured in air or in the absence of oxygen.The curing in the absence of oxygen wasachieved using three different types of oxygen inhibitors: (1) medical glycerine, (2) Liquid Strip( IvoclarVivadent AG, Schaan, Liechtenstein), (3) OXYGUARDII, PANAVIA F 2.0 (Kuraray, Tokyo, Japan).Specimens were assessed forcolor stability after immersion in a staining solutionfor 7 days. The results were analyzed by one-way ANOVA to analyze color difference $(\Delta \mathrm{E})$, and Tukey's test, was applied for bilateral comparisons between study groups.

Results: The highest $\Delta \mathrm{E}$ value was $(2.3 \pm 0.5)$ for control group followed by $(2.2 \pm 0.4)$ for Liquid Strip and Oxyguard groups. However, the lowest $\Delta \mathrm{E}$ value was $(2.1 \pm 0.4)$ for medical glycerin $(\mathrm{p}=0.870)$. There was no significant difference between the study groups.

Conclusions: Color stability is not affected by the commercial type of oxygen inhibitor and the finishing is enough to remove the oxygen inhibited layer if it is possible well done.

Keywords: Oxygen Inhibited Layer; Glycerin; Monomer.

\section{Introduction}

Resin cements are low-viscosity composite materials with filler distributionmodified to allow for a low film thickness and appropriate working and setting times [1]. They are used for many applications, from inlays to fixed bridges, prefabricated posts and porcelain laminate veneers [2]. Resin cements are classified by activation mode to light cureor chemical cure or dual cure (combinations of light and chemical) [3].

The main advantages of light-cured resin cements for dual-cure and chemical-cure systems are color stability, and control of the working time [4]. Furthermore, the short curing time makes lightcured systems less sensitive to oxygen inhibition when compared with the chemically cured systems [2].
However, the propagating free radicalsare attracted to oxygenmore than the monomer molecule during the polymerization reaction in adhesive systems, and are oxidized into peroxy radicals, which don't have relatively reactivity toward the monomer and form peroxides, turning off polymerization if they interact [5].

$\mathrm{R} \bullet+\mathrm{O} 2 \rightarrow \mathrm{R}-\mathrm{OO} \bullet($ stable radical) $[6]$

This causes the formation of an oxygen inhibition layer on the superficial surface of light-cured resin cements and composite resin materials when these are cured in the presence of air. This sticky layer has a lot of unreacted monomers and oligomers, It is readily adopts overlying resin cements to make their contact area high and allows materials on both sides to correlate, creating a strong chemical bond [7,8]. Previous studies have reported an oxygen inhibition layer (OIL) thickness for resin- based materials ranging from $\sim 4[9]$ to $40 \_\mathrm{m}[10,11]$ and 200 microns in some

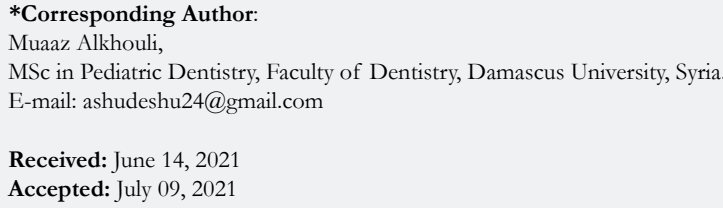

Citation: Ali Yousef, Eyad Swed, Kinan Saoud, Muaaz Alkhouli. Comparative Study Of Effect Of Many Commercial Types Of Oxygen Inhibitors On Resin Cement. Int J Dentistry Oral Sci. 2021;8(7):3408-3411. doi: http://dx.doi.org/10.19070/2377-8075-21000692

Copyright: Muaaz Alkhouli 2021 . This is an open-access article distributed under the terms of the Creative Commons Attribution License, which permits unrestricted use, distribution and reproduction in any medium, provided the original author and source are credited. 
studies [12].

This resin-rich uncured layer affects the surface texture leading to a porous and weak structure, therefore plaque can accumulate and gingival inflammation develop on the edges of the restoration. furthermore, that porous surface can explain discoloration and influences the prognosis of dental restoration reducing its hardness and marginal adaptation $[13,14]$.

Last reasons have made the complete removal of oxygen inhibition layer in the interest scope of researchers. recently, topical application of glycerin was reported to be used on external surfaces of resin composite restorations and margins of indirect restorations and the results are encouraging [15].

Glycerin is hygroscopic, and Pure glycerin is not oxidized by the atmosphere, Glycerin concentration differs with solvent type,mixtures of glycerin with water, ethanol (95\%), and propylene glycol are chemically stable [16].

The purpose of the present study was to compare the effect of many commercial types of oxygen inhibitor on color stability of resin cement and the null hypothesis was that there is no difference.

\section{Materials and Methods}

\section{Preparation of samples}

40 discs were milled by CAD/CAM from PMMA(poly methyl methacrylate), shade A2 (figure1). The dimensions of the disc were ( external diameter $14 \mathrm{~mm}$,internal diameter $10 \mathrm{~mm}$ ). The light-cured resin cement used in this study was Variolink-N (, IvoclarVivadent AG, Schaan, Liechtenstein) shade A2, and was inserted into the PMMA mold (thickness, $1 \mathrm{~mm}$ ) at a temperature of $23^{\circ} \mathrm{C}$.

Every specimen was placed on a dental vibrator to reduce possible voids causing by entrapped air on the uncured resin cementl inside the mold( figure2) and a microscope glass slab was gently pressed on the top surface of the specimen to extrude the excess material and, ensure a smooth surface.

The specimens were light cured using an LED curing device (Woodpecker Light Cure Led, Guangdong, China ), which produces blue light with a wavelength of $420-480 \mathrm{~nm}$ and an output intensity of $1300 \mathrm{~mW} / \mathrm{cm} 2$ for 40 seconds, and the light guide tip was directly placed at a distance of $1 \mathrm{~mm}$ from the specimen's surface (figure 3). The light intensity was checked every 3 samples with a radiometer to ensure consistent light output throughout the study.

The discs were randomly numbered from 1 to 40 on the bottom using a high speed small round bur and divided into four main groups $(n=10)$ based on different commercial types of glycerin : Group A: Specimens polymerized without any barrier between the surface of the resin composite and the light curing tip.( only finishing after the polymerization).

Group B: Specimens polymerized using a layer of medical glycerin applied on the surface of the composite prior to light-curing procedures (figure 4).

Group C: Specimens polymerized using a layer of glycerin (Liquid Strip, IvoclarVivadent AG, Schaan, Liechtenstein) applied on the surface of the composite prior to light-curing procedures(figure 5).

Group D: Specimens polymerized using a layer of glycerin (OXYGUAR II, PANAVIA F 2.0 ,Kuraray, Tokyo, Japan) applied on the surface of the composite prior to light-curing procedures.

Every specimen was prepared and cured in a room with yellow light to avoid any unwanted effects from surrounding light sources.

All specimens were finished for 15 seconds using a composite finishing bur (852.016.Coltene/Whaledent G, Altstätten ,Switzerland), and then exposed to thermocycling for 5,000 cycles between $5^{\circ} \mathrm{C}$ and $55^{\circ} \mathrm{C}$ water temperature, with a 30 second dwell time (Thermocycler, GMBH, MiebacherStrabe, Germany).

\section{Color Stability Evaluation}

All the specimens were stored in $37^{\circ} \mathrm{C}$ distilled water for $24 \mathrm{~h}$. To evaluate color, the specimens were placed onto a white background and a drop of distilled water was placed in the space between the disc and the backing to confirm that the specimen was in perfect contact with the backing during the spectrophotometric measurements. All initial assessments were performed by one trained operator usinga spectrophotomer( Vita Easy Shade; Wilcos, Rio de Janeiro, Brazil) (figure 6) and the CIE Lab system of color and.3 measurements were performed in the central area of each sample and the mean was calculated (L0, a0 ,b0). A calibration was done for the spectrophotometer every 5 measurements.

After initial measurements, every specimen was coated with a layer of nail varnish except the surface was coated from the borders of the disc to $1 \mathrm{~mm}$ of resin cement, then all specimens were immersed in a staining solution coffee (Nescafé, Gran Aroma coffee soluble, $6 \mathrm{~g}$ in $200 \mathrm{~mL}$ of distilled water) for 7 days at $37^{\circ} \mathrm{C}$. The staining solution was replaced every day to avoid excessive bacterial proliferation. After 7 days, nail varnish was removed using acetone All specimens were soaked in distilled water for 5 minutes then dried with paper. and the spectrophotometric measurements were recorded (L1, a1, b1).

The color change values $(\Delta \mathrm{E})$ between the specimens after immersion in coffee and initial values were calculated from the mean $\mathrm{DL}^{*}, \mathrm{Da}^{*}$ and $\mathrm{Db}^{*}$ values for each specimen with using the following formula:

$\Delta \mathrm{E}=\left\{(\Delta \mathrm{L})^{2}+(\Delta \mathrm{a})^{2}+(\Delta \mathrm{b}) 2\right\}^{1 / 2}$

Normal distribution of data was assessed by applying the Shapiro-Wilk test. One-way ANOVA test was used to analyze color difference $(\Delta \mathrm{E})$, and Tukey's test, was applied for bilateral comparisons between study group.

\section{Results}

The means \pm standard deviation of $\Delta \mathrm{E}$ values for different study 
Table 1. Description statistic for $\Delta \mathrm{E}$ values in study groups.

\begin{tabular}{|c|c|c|}
\hline Group & Mean & Standard Deviation \\
\hline A & 2.3 & 0.5 \\
\hline B & 2.1 & 0.4 \\
\hline C & 2.2 & 0.4 \\
\hline D & 2.2 & 0.4 \\
\hline
\end{tabular}

Figure 1. Means \pm standard deviations of $\Delta \mathrm{E}$ values after immersion in coffee.

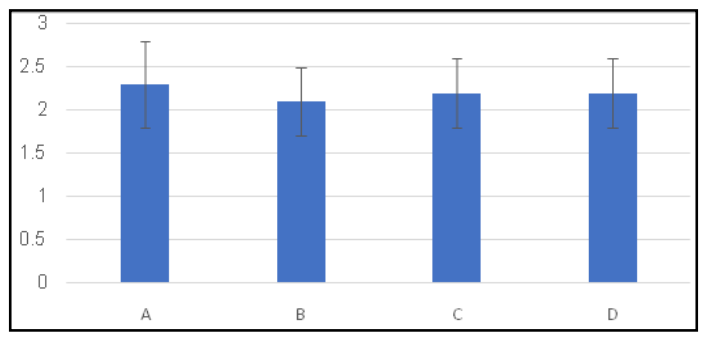

groups are shown in Table 1 . The highest $\Delta \mathrm{E}$ value was $(2.3 \pm$ $0.5)$ for control group followed by $(2.2 \pm 0.4)$ for Liquid Strip and Oxyguard groups. However, the lowest $\Delta \mathrm{E}$ value was $(2.1 \pm 0.4)$ for medical glycerin $(\mathrm{p}=0.870)$. One- way ANOVA results showed that $\Delta \mathrm{E}$ values were not significantly affected by the commercial type of oxygen inhibitorand Tukey's results indicated no statistically significant difference between groups.

\section{Discussion}

The degree of conversion (DC) is the percentage ratio of the amount of monomers converted in a polymer during the polymerization [2], and the level of DC influences the aesthetic and mechanical properties of resin luting agents such as hardness, surface roughness and color stability [17]. The oxygen inhibited layer is rich in unreacted monomers and this results in less degree of conversion (DC) [18]. Therefore, causes marginal discoloration of the indirect restoration cemented by resin cements [19]. So in this study, color stability of resin cement has been studied as an indirect method to evaluate the effect of oxygen inhibitors on preventing oil formation.

There are many factors can cause staining of resin cement. Intrinsic factors such as initiator type, filler size and hydrolysis in theresin matrix [20, 21]. For last reason, the type of resin cement and the distance between the specimen and the curing device were uniform in all study groups. The resin cement thickness $(1 \mathrm{~mm})$ is much higher than the clinical thickness, This was for reliable results because the spectrophotometers require a certain sample thickness according to the ISO standards [22] and due to the limitations of the in vitro testing methods.

In this study, The staining solution was coffee because it is usual drunk routinely by patients with a high potential to stain resin cement, and Nail varnish was used to ensure that only the superficial surface has been affected by coffee. Furthermore, finishing time was equal for all the specimens because the surface texture is one of the extrinsic factors that can cause discoloration and finishing is required after adhesion with resin cement [15]. The specimens were immersed in distilled water to mimic the oral environment and because the polymerization reaction finishes within $24 \mathrm{~h}$ after the curing.In this study, the CIE L*a*b* system was used, since this method remains the most accuratemethod to measure the color stability [23].

$\Delta \mathrm{E}$ values in all study groups were $<3.3$ and $>1.1$ which means that discoloration of resin cement was perceptible to the human eye but clinically acceptable [18], and the results showed that no significant differences were found between the groups. So, The null hypothesis of this study was acceptedand there was not difference in color stability with the type of oxygen inhibitor.Furthermore, no significant difference was found betweenthe control group and the other groups, which confirms that finishing was sufficient to remove the oxygen inhibited layer and this agrees withTopaloglu-Ak et al 2020 [13] andStrnad Get al 2015 [14] in the role of finishing and polishing for removing the oil whereas the finishing can remove $0.2 \mathrm{~mm}$ from the surface of resin cement. By contrast, Marigo Let al 2019 [18] tested Influence of different air-Inhibition coatings on color stability, but reported thatthe use of glycerin may be suitable for light-curing procedures and improve the chemicophysical and aesthetics properties.

\section{Conclusion}

There is no difference between the commercial types of oxygen inhibitors in this study, and finishing is enough to remove the oxygen inhibited layer if it is possible well done.

\section{References}

[1]. Anusavice KJ. Reducing the failure potential of ceramic-based restorations. Part 2: Ceramic inlays, crowns, veneers, and bridges. Gen Dent. 1997 JanFeb;45(1):30-5.Pubmed PMID: 9171476.

[2]. Anusavice KJ, Shen C, Rawls HR, editors. Phillips' science of dental materials. Elsevier Health Sciences; 2012 Sep 27.

[3]. Niemi A, Perea-Lowery L, Alaqeel SM, Ramakrishnaiah R, Vallittu PK. Dual-curing resin cement with colour indicator for adhesively cemented restorations to dental tissues: Change of colour by curing and some physical properties. Saudi J Biol Sci. 2020 Jan;27(1):395-400.Pubmed PMID: 31889862.

[4]. Espíndola-Castro LF, Brito OFF, Araújo LGA, Santos ILA, Monteiro GQM. In Vitro Evaluation of Physical and Mechanical Properties of Light-Curing Resin Cement: A Comparative Study. Eur J Dent. 2020 Feb;14(1):152-156. Pubmed PMID: 32168541.

[5]. Ouchi H, Tsujimoto A, Nojiri K, Hirai K, Takamizawa T, Barkmeier WW, et al. Effect of Oxygen Inhibition Layer of Universal Adhesives on Enamel Bond Fatigue Durability and Interfacial Characteristics With Different Etching Modes. Oper Dent. 2017 Nov/Dec;42(6):636-645.Pubmed PMID: 


\section{8}

[6]. Gauthier MA, Stangel I, Ellis TH, Zhu XX. Oxygen inhibition in dental resins. J. Dent. Res. 2005 Aug;84(8):725-9.

[7]. Yamaji A, Tsujimoto A, Asaoka T, Matsuyoshi S, Tsuchiya K, Takamizawa T, et al. Effect of oxygen inhibition in two-step self-etch systems on surface free energy and dentin bond strength with a chemically cured resin composite. J Oral Sci. 2014 Sep;56(3):201-7.Pubmed PMID: 25231146.

[8]. Koga K, Tsujimoto A, Ishii R, Iino M, Kotaku M, Takamizawa T, et al. Influence of oxygen inhibition on the surface free-energy and dentin bond strength of self-etch adhesives. Eur. J. Oral Sci. 2011 Oct;119(5):395-400.

[9]. Finger WJ, Lee KS, Podszun W. Monomers with low oxygen inhibition as enamel/dentin adhesives. Dent Mater. 1996 Jul;12(4):256-61.Pubmed PMID: 9002844.

[10]. Rueggeberg FA, Margeson DH. The effect of oxygen inhibition on an unfilled/filled composite system. J Dent Res. 1990 Oct;69(10):1652-8.Pubmed PMID: 2212209.

[11]. Shawkat ES, Shortall AC, Addison O, Palin WM. Oxygen inhibition and incremental layer bond strengths of resin composites. Dent Mater. 2009 Nov $1 ; 25(11): 1338-46$

[12]. Park HH, Lee IB. Effect of glycerin on the surface hardness of composites after curing. J Korean Acad Conserv Dent. 2011 Nov 1;36(6):483-9.

[13]. Topaloglu-Ak A, Çayırgan D, Uslu M. Evaluation of Surface Roughness of Composite, Compomer and Carbomer After Curing Through Mylar Strip and Glycerin: A Comparative Study. J. Adv. Oral Res. 2020 May;11(1):12-5.

[14]. Strnad G, Kovacs M, Andras E, Beresescu L. Effect of curing, finishing and polishing techniques on microhardness of composite restorative materials. Proc. Technol. 2015 Jan 1;19:233-8.

[15]. Sahbaz C, Bahsi E, Ince B, Bakir EP, Cellik O. Effect of the different finishing and polishing procedures on the surface roughness of three different posterior composite resins. Scanning. 2016 Sep;38(5):448-54.

[16]. Rowe RC, Sheskey P, Quinn M. Handbook of pharmaceutical excipients. Libros Digitales-Pharmaceutical Press; 2009;648:703.

[17]. Tosco V, Monterubbianesi R, Orilisi G, Sabbatini S, Conti C, Ozcan M, et al. Comparison of two curing protocols during adhesive cementation: can the step luting technique supersede the traditional one? . Odontology. 2020.

[18]. Marigo L, Nocca G, Fiorenzano G, Callà C, Castagnola R, Cordaro M, et al. Influences of Different Air-Inhibition Coatings on Monomer Release, Microhardness, and Color Stability of Two Composite Materials. Biomed Res Int. 2019 May 9;2019:4240264.Pubmed PMID: 31211136.

[19]. Nocca G, Iori A, Rossini C, Martorana GE, Ciasca G, Arcovito A, et al. Effects of barriers on chemical and biological properties of two dual resin cements. Eur J Oral Sci. 2015 Jun;123(3):208-14.Pubmed PMID: 25735897.

[20]. Alawjali SS, Lui JL. Effect of one-step polishing system on the color stability of nanocomposites. J. Dent. 2013 Aug 1;41(Suppl 3):e53-61.

[21]. Castellanos M, Delgado AJ, Sinhoreti MAC, de Oliveira DCRS, Abdulhameed N, Geraldeli S, et al. Effect of Thickness of Ceramic Veneers on Color Stability and Bond Strength of Resin Luting Cements Containing Alternative Photoinitiators. J Adhes Dent. 2019;21(1):67-76.Pubmed PMID: 30799473.

[22]. Kilinc E, Antonson SA, Hardigan PC, Kesercioglu A. Resin cement color stability and its influence on the final shade of all-ceramics. J Dent. 2011 Jul;39 Suppl 1:e30-6. PubmedPMID: 21241766.

[23]. Vaz EC, Vaz MM, de Torres ÉM, de Souza JB, Barata TJE, Lopes LG. Resin Cement: Correspondence with Try-In Paste and Influence on the Immediate Final Color of Veneers. J Prosthodont. 2019 Jan;28(1):e74-e81. Pubmed PMID: 29314449. 